\title{
Preface
}

\section{An introduction to the 1st European Space Weather Week (ESWW)}

This special issue of Annales Geophysicae presents the scientific papers from the 1st European Space Weather Week (ESWW) which was held at ESTEC (Noordwijk) from Monday, 29 November to Friday, 3 December, 2004.

This meeting was the result of long and patient work that started about ten years earlier involving many European entities. Indeed, it is in 1996 that an ESA roundtable on Space Weather was organised to discuss possible options for a European counterpart to the US National Space Weather Programme. The 1st Space Weather workshop happened two years later. At this time, the community was developing, and the perspective for a coordinated effort in the field of Space Weather was being investigated. We had hot debates about the goals: research or industry? User driven or laboratory driven? Many questions were discussed with lots of enthusiasm.

ESTEC has maintained a key role in structuring the field in Europe, primarily by organising a yearly workshop from 1998 to 2003. In parallel, it funded a study on the feasibility of a European Space Weather Programme. Two broad international consortia were appointed; one under the leadership of RAL (UK) and one under the leadership of LPCE and Alcatel (France). In order to coordinate these two consortia, the Space Weather Working Team (SWWT) was created and initially chaired by R. Gendrin. The results of the two parallel studies were published in 2001 (http://www.estec.esa. nl/wmwww/wma/spweather/). Several strategies were proposed to develop Space Weather in Europe. From these studies it was clearly demonstrated that Europe has very strong assets which could be potentially exploited in European or International Space Weather services. These assets include:

- Ground-based solar, ionospheric, cosmic ray and geomagnetic observatories.

- Nano and Micro-satellite expertise;

- Existing and planned space mission assets (e.g. SOHO, Cluster, Galileo);

- Strong theoretical groups with skills in modelling;

- Strong expertise in Space Weather effects;

- Already existing small-scale Space Weather services.

It was clearly understood that the coordination and development of Space Weather services would enhance the efficiency of these activities and provide new opportunities for the use of resources across domains that are currently separated from each other.

The SWWT continued to be active in its advisory role following the end of the two parallel studies. One of the recommendations of the SWWT was to create a COST (COordination in the field of Science and Technology) action targeted at the science underpinning Space Weather. The COST proposal was accepted by the Brussels administration and was inaugurated in November 2003 under the number 724. In 2005 , it coordinates the Space Weather theoretical related efforts of 26 countries.

In addition, at this time, one COST action was already at work in the field of Space Weather: COST 271 (followed by COST 296 in 2005) had been very successful in studying the effects of Space Weather on the ionosphere and wave propagation. In parallel, the European Science Foundation promoted the scientific network SPECIAL (Space Processes and Electrical Charges Influencing Atmospheric Layers), to discuss the impact of solar activity on climate change, which may be followed by a EUROCORE project called E-STAR (European Solar-Terrestrial and Atmospheric Research). In addition to these activities, European scientific missions with relevance to Space Weather are currently being discussed within the framework of the International Living with a Star Programme.

Following on from the 2 parallel feasibility studies, in 2003 ESA embarked upon a 2-year Space Weather Applications Pilot Project. The aim of this project is to develop and extend the Space Weather user community through the development of targeted services, provided by a network of service providers, supported by a common infrastructure and using data from existing or easily adaptable assets. Through this service and community development a long-term view of the potential for Space Weather applications is established.

The Space Weather Pilot Project consists of three main components:

1. a network of service development activities (SDA) involving service providers, users and data providers,

2. an infrastructure development, coordination and support activity, and

3. a quantitative evaluation of the costs and benefits of a European Space Weather service, based on, but not limited to, information received from the other elements of the pilot project. 
At the time of writing, the pilot projects incorporate 17 ESA co-funded Service Development Activities (SDAs) and a number of additional independently funded SDAs, each focusing on a wide range of Space Weather user domains. In addition to the individual service activities, a service support infrastructure was created. Together with the SDAs, this infrastructure, and consequently the pilot project as a whole, is named the "Space Weather European NETwork" (SWENET). This activity provides support to the SDA activities, and forms the centralised web-based access point to a coordinated network of European Space Weather services. This service network activity is done in collaboration with the International Space Environment Service and the NOAA Space Environment Center.

In view of so many collaborative efforts and so much enthusiasm, it was not surprising that the annual ESA Space Weather Workshop became known as a European Space Weather Week. The fact that the organising committee included participants of each of these initiatives shows their degree of confidence and good will to collaborate. During this 1st European Space Weather Week, reviews were given of the status of the ESA Space Weather Applications Pilot Projects, together with work carried out within the framework of the COST actions, E-Star and other ventures. The workshop also focused on how to co-ordinate efforts within Europe, to provide the best services for potential users, and included brainstorming on the next steps towards a coordinated, sustainable, long-term Space Weather effort.

The 1st European Space Weather Week was divided into 7 sessions. Five of these sessions focused on the Science-to-Applications topics of Radiation Environment of the Earth/Spacecraft and Aircraft Environment, Ionosphere/Positioning and Telecommunication, Magnetic Environment/GICs and Other Ground Effects, Atmospheres/Drag, Global Change and Solar Weather/Solar Activity forecast and predictions. An additional two sessions addressed the business aspects in the context of Agencies Activities and Outreach to Communities, Emerging Markets and Education.
A large number of splinter meetings took place, which covered both scientific and operational themes. Topics included recent unusual Space Weather activity, technical meetings of the ESA Space Weather Applications Pilot Project, a management committee meeting of the COST 724 action, together with several related technical meetings, a coordination meeting of the upcoming E-STAR EUROCORES programme and several meetings related to diverse Space Weather Working Team (SWWT) activities.

Overall, it was felt that this 1st European Space Weather Week clearly demonstrated the presence of an active Space Weather community in Europe, and the benefits of bringing together scientific and applications oriented activities. It was decided that this event should become an annual meeting, as its US counterpart, with the goal of pursuing future European actions in the field of Space Weather. Following this 1st European Space Weather Week, a number of actions are presently being investigated with this goal in mind. These include the potential contribution of the European Space Weather Community to the upcoming I*Y initiatives, mechanisms for coordination of Space Weather related initiatives, and a number of potential activities within the scope of the EC's Framework Programmes for Research.

Important follow-on activities also include the publication of this Annales Geophysicae special issue which is comprised of scientific poster contributions from the ESWW. The aim is to demonstrate the European state of the art in the science underpinning Space Weather. We hope that the reader will enjoy this special issue and find many new and interesting items!

J. Lilensten, A. Glover, A. Hilgers, A. Belehaki, F. Lefeuvre, H. Opgenoorth, B. Zolesi, M. Fuellekrug

Special Issue Editors 